\title{
From the Editor of Sexuality and Disability: The Impact of COVID-19 on Sexuality and Disability-Are We Closer or More Isolated?
}

\author{
Sigmund Hough ${ }^{1}$
}

Published online: 24 April 2020

(c) Springer Science+Business Media, LLC, part of Springer Nature 2020

The journal, Sexuality and Disability, continues to be a professional home and a place of professional rejuvenation for study. Many have followed the journal over the decades since the 1970's. If you are new to the journal, we give to you a "BIG WELCOME" and invite you to participate as a reader, author, academician, clinician, educator, service provider, researcher, advocate, or person seeking information. Over the years of contribution to the literature on sexuality and disability healthcare, we have been a part of the growth, understanding, and advocacy. Most important, we continue to be a part of the change in how we look and examine the topic, the needs, and the response in terms of best practice- evidence based approaches. With the intelligence, experience, motivation, and supportive dedication from our authors, readership, international peer reviewers and editorial board members, and resources combined with valuable guidance from the Springer Staff; our journal's mission continues to be meaningful. This international effort continues as a strength in the field of sexuality and disability.

Since 1978, Sexuality and Disability has pushed for pragmatic knowledge to have impact on education, research, and practice. Sexuality and Disability makes available original impact articles addressing the mental health and medical healthcare aspects of sexuality in relation to rehabilitation, hospital, academic, and community settings, publishing upto-date articles, case studies, clinical practice reports, reviews, featured articles, historical articles, special grand rounds topics, brief research reports, and survey data reports. Value benefit is provided to authors through worldwide electronic exposure and professional access, while readership gains knowledge from scholarly contributions which advance the field through research, evidence-based, best-practice and educational articles. Individual contributions from the local and international community delivers a wealth of information with broad perspectives on the topic of sexuality and disability.

The Coronavirus Disease (COVID-19) is a paramount challenge for the world, as we start 2020. Healthcare preparation and management, life and death decisions, financial and economic instability, are some of the issues that present in the News every day and we are confronted with every hour of every day. We hope that you and your family will be safe and well, as we move forward.

Sigmund Hough

Sigmund_Hough@hms.harvard.edu

Beverly, MA, USA 
In terms of the journal's scope, there is an opportunity to investigate the impact of this pandemic upon sex and sexual activity, dating and relationships, social media and social distancing. Are we providing the proper education and support to meet individual need or as a requirement to check-off? Has online dating increased? Has sexy texting increased? Who has access to alternative activities? What has happened to scheduled surrogate sessions, therapeutic massage treatment? Does the need disappear during quarantine, over days, weeks, months? We invite readership to consider contributing to the literature through a 360 perspective lens on these multi-faceted issues.

Thank you for joining our professional efforts.

Sigmund Hough, Ph.D., ABPP/rp

Editor-in-Chief, Sexuality and Disability

Publisher's Note Springer Nature remains neutral with regard to jurisdictional claims in published maps and institutional affiliations. 